\title{
The Circuit and Network Analysis of Some Signal Separation Structures Constituting Microwave Six-Port Reflectometers
}

\author{
R. Piña Piña ", A. Dueñas Jiménez, C. A. Bonilla Barragán \\ Departamento de Electrónica, División de Electrónica y Computación, Centro Universitario de Ciencias Exactas e Ingenierías, Universidad \\ de Guadalajara, 45030 Guadalajara, Jalisco, México \\ *Corresponding Author: reydi2p@hotmail.com
}

Copyright (C) 2014 Horizon Research Publishing All rights reserved.

\begin{abstract}
The circuit and network analysis of some signal separation structures constituting a microwave six-port reflectometer are presented. An interconnection of five of these structures composing a six-port network analyzer is also presented. In order to validate the responses, a circuit analysis following the signals from source to detectors, is performed. The complete structure constituting the six-port network analyzer is composed by a $6 \mathrm{~dB}$ directional coupler, a four stage $3 \mathrm{~dB}$ Wilkinson power divider and three quadrature couplers providing $3 \mathrm{~dB}$, which are formed by two $8.34 \mathrm{~dB}$ tandem couplers.
\end{abstract}

Keywords Six-Port Reflectometry, Circuit And Network Analysis, Broadband Couplers, Electromagnetic Validation

\section{Introduction}

The six-port structures are used to build reflectometers and network analyzers. A six-port reflectometer is a system to indirectly measure the reflection coefficient (magnitude and phase) of passive and active one-port and n-port devices (port-by-port) on a reference plane located at the device itself or at any point of a transmission line. Thus, this instrument allows determine the reflection characteristics of general transmission line circuits. By his part, a dual six-port network analyzer can measure the transmission characteristics besides the reflection ones. In this paper, the circuit and network analysis properties are profited to design a single six-port reflectometer composed by a $6 \mathrm{~dB}$ directional coupler, a four stage $3 \mathrm{~dB}$ Wilkinson power divider and three quadrature couplers providing $3 \mathrm{~dB}$, which are formed by two $8.34 \mathrm{~dB}$ tandem couplers (Fig. 1); and a dual six-port network analyzer composed by the interconnection of two single six-port reflectometers (Fig. 2).

Owing to the wide bands and the diverse couplings required by the six-port structures constituting the reflectometers and network analyzers, the structures have to be conceived as to be implemented on multi-layer technology. Thus, an advisable alternative to design a wide band $3 \mathrm{~dB}$ quadrature coupler will be conceiving it as a cascade connection of two $8.34 \mathrm{~dB}$ directional couplers [1,2]. This technique requires divide the circuit into two conducting layers separated by a very thin dielectric, and sandwich them between two grounded dielectrics as shown in Fig. 3. The same criteria of using the three layer structure of Fig. 3 can also be applied for the $6 \mathrm{~dB}$ coupler since this divider requires as well a large coupling. On the contrary, for the in phase $3 \mathrm{~dB}$ coupler a single layer structure can be used since this divider may be conceived as a multi-section Wilkinson power divider [3]. The Wilkinson couplers are not four port devices, therefore, on the contrary to the original Engen's four-port [4], they do not require of a $50 \Omega$ load. However, despite this advantages and because they are Wilkinson type couplers, it will be necessary to use shunt connected resistive elements at the junction of each section.

Thus, although the Wilkinson couplers of several sections could be implemented on one layer structures, this will complicate the complete integration with other multi-layer signals separation structures, since the aperture of some connection windows will be necessary on the top dielectric. Before numbering the steps to design the signal separation structures, it is important to mention that, the original idea was to design the six-port for a bandwidth of 2 to $8 \mathrm{GHz}$, but owing to the design restrictions (mainly because of the manufacturer's fixed dimensions of the dielectrics) only a bandwidth of $3.5 \mathrm{GHz}(1.25$ to $4.75 \mathrm{GHz})$ was obtained. This limitation on the bandwidth is generated because the three layer structures should share the same dimensions on their dielectric thickness and conducting layers. The steps to design the signal separation structures (Q1, Q2, Q3, $6 \mathrm{~dB}$ and $\mathrm{H}$ ) in order to obtain a priori known of their dimensions, and for planning its final incorporation on the six-port structure are next listed.

\section{Design of the Quadrature $3 \mathrm{~dB}$ Coupler}


To design the $3 \mathrm{~dB}$ directional couplers (Q1, Q2 and Q3), the Cristal design tables [5] and the cascade design alternative proposed by Shelton[1], were both advantageously employed. In the Shelton alternative, two $8.34 \mathrm{~dB}$ directional couplers are interconnected to obtain (both couplers in conjunct) the response of one of $3 \mathrm{~dB}$ in quadrature. This arrangement was chosen because the interconnection must be mandatorily realized by crossing the lines of the $8.34 \mathrm{~dB}$ couplers and because, to get simultaneously the maximum coupling, the necessary width on the central section should be not extremely thin. Thus, it was determined that, the best option to realize the couplers was to use different layers separated by a very thin dielectric. Fig. 4 shows how two interconnected $8.34 \mathrm{~dB}$ couplers form a $3 \mathrm{~dB}$ one. The 1 and 2 ports are located in a same layer while the ports 3 and 4 are placed on another.

Now then, to obtain a wide bandwidth from both, the $6 \mathrm{~dB}$ couplers and the $3 \mathrm{~dB}$ quadrature couplers, it is necessary to conceive it as being composed by several sections of coupled lines each one with a specific coupling and with a $\lambda / 4$ length at the operation frequency.

For designing the $6 \mathrm{~dB}$ and $3 \mathrm{~dB}$ quadrature couplers, it is necessary to solve polynomial equations to obtain the normalized values of even and odd mode impedances. With the availability of these values it is possible to calculate the coupling $\rho$ or the voltage coupling coefficient $c_{v}$ (also known as $k_{v}$ ) relationships that should have each section. The coupling coefficient values will vary as a function of the coupling value desired for the all coupler, as a function of the required bandwidth, as a function of the necessary number of sections and as a function of the maximum variation of coupling (in $\mathrm{dB}$ ) inside the bandwidth (the ripple value).

The polynomial equations become more complex as more sections are required. However, it is not necessary a direct calculation of them since, fortunately Cristal presented tables with even impedance values for a large number of combinations. The tables show only the half of the values normalized to the design impedance since the structures are symmetric (this is, its values are repeated starting from the central section to the edges).

To design the $8.34 \mathrm{~dB}$ couplers by means of the Cristal tables, the values for one of seven sections, with a ripple of \pm $0.15 \mathrm{~dB}$, corresponding to a bandwidth $(B)$ of approximately 6.6 times the initial $\left(f_{1}\right)$ frequency, are chosen. These values are shown in Table 1 . If $f_{1}=1.25 \mathrm{GHz}$, the chosen $B$ value will allow a bandwidth covering from 2 to $8 \mathrm{GHz}$ but sadly the final bandwidth of the entire six-port will be fixed by the coupler with the lesser individual bandwidth, in this case that of the $6 \mathrm{~dB}$ coupler.

The seven sections that conforms each one of the $8.34 \mathrm{~dB}$ couplers are synthesized in the following way:

The central section is synthesized for maximum coupling which is attained by a total shifting of the conducting lines widths, one over the other. This configuration is called "Broadside" and is shown in Fig. 5a.

All the other sections are synthesized for a minor coupling which is obtained by using a determined conduction lines shifting known as "Offset". The amount of dislodgement depends on the coupling; this is, for a lesser coupling a larger displacement. The "Offset" configuration is shown in Fig. $5 b$.

Table 1. Even impedance, normalized zoe and not normalized Zoe, for an $8.34 \mathrm{~dB}$ coupler of seven sections, with a normalizing impedance of $50 \Omega$.

\begin{tabular}{|c|c|c|c|c|c|}
\hline $\begin{array}{l}\text { Ripple } \\
\text { in } \mathrm{dB}\end{array}$ & zoe1 & zoe2 & zoe3 & zoe4 & $B$ \\
\hline \pm 0.15 & 1.02519 & 1.08680 & 1.24872 & 2.06076 & 6.6655 \\
\hline $\mathrm{Z} 0=50 \Omega$ & Zoe1 & Zoe2 & Zoe3 & Zoe4 & \\
\hline & $51.25 \Omega$ & $54.34 \Omega$ & $62.436 \Omega$ & $103.038 \Omega$ & \\
\hline
\end{tabular}

In figures 5 , the $\mathrm{B}$ value corresponds to the separation between the two ground planes and $w$ indicates a same width for the two lines. The distance " $s$ " denotes the separation between the two lines (imposed by the thickness of the chosen commercial dielectric) [6]. For the specific case of the "Offset" configuration, $w_{\mathrm{o}}$ (large couplings) is the separation or dislodgement between the lines, and $w_{\mathrm{c}}$ (small couplings) is the distance or length of the dislodgement [2].

Thus, the seven sections that conforms an $8.34 \mathrm{~dB}$ coupler are synthesized as shown in Fig. 6 .

Then, from the normalized values of Table 1 , the coupling coefficients are calculated by employing the following equation:

$$
c_{v n}=\frac{\mathbf{z o e}_{n}^{2}-1}{\mathbf{z o e}_{n}^{2}+1},
$$

where $c_{v n}$, denotes the voltage coupling coefficients and $n$ is the section number. Thus, the values of $c_{v n}$ are shown in Table 2. These coupling values are then introduced in a code that apply the Bahl equations [6] for the central section and the Shelton equations [2] for the remaining sections. To solve these sets of equations, it is necessary to enter, besides the coupling coefficients, the characteristics and physical dimensions of the material that will be used to synthesize each specific section. In what follows, the difficulties affronted to choose a correct combination of conducting films and dielectric thickness are mentioned.

Table 2. Coupling coefficients for an $8.34 \mathrm{~dB}$ coupler of seven sections.

\begin{tabular}{|c|c|c|c|c|c|}
\hline $\begin{array}{c}\text { Ripple } \\
\text { in dB }\end{array}$ & zoe1 & zoe2 & zoe3 & zoe4 & $B$ \\
\hline \pm 0.15 & 1.02519 & 1.08680 & 1.24872 & 2.06076 & 6.6655 \\
\hline zoe $_{n}^{2}$ & 1.0510 & 1.1811 & 1.5593 & 4.24673 & \\
\hline$c_{v n}$ & 0.024873 & 0.083046 & 0.218537 & 0.61881 & \\
\hline
\end{tabular}

Initially, the dimensions of the dielectrics and conductors employed by Rao[7] were chosen. Rao used an optimization program that forced some of the specifications to coincide with a set of determined ones. However, after a lot of tests, the reproduction of the Rao values was impossible, so, the decision to work with not forced specifications was adopted.

Besides, the choosing of the layer dimensions was depending not only of the design necessities of the $3 \mathrm{~dB}$ 
quadrature coupler but also of those of $6 \mathrm{~dB}$ coupler since both will be implemented over the same layers.

Finally, a combination of thicknesses for the dielectrics and conductors permitting that both couplers be implemented together was found. Unfortunately, about $40 \%$ of the $6 \mathrm{~dB}$ bandwidth had to be sacrificed.

Thus, since the $3 \mathrm{~dB}$ quadrature coupler is formed by two of $8.34 \mathrm{~dB}$, the configuration of the final coupler will be as shown in Fig. 7.

The dimensional and electrical characteristics employed for the triple-layer structure and forced by the commercial availability of the RT/Duroid $5880^{\circledR}$ plates of Rogers, are as follows: the central plate is Duroid $5880^{\circledR}$ with a relative permittivity of $\varepsilon_{r}=2.2$, thickness of $0.010 "(0.254 \mathrm{~mm})$ corresponding with the value of $s$ in Figs. 5, and with cooper conducting films of $17 \mu \mathrm{m}$ of thickness $(0.017 \mathrm{~mm})$. The top and bottom plates are also of Duroid $5880^{\circledR}$ with $\varepsilon_{r}=2.2$, but with thickness of 0.031 " $(0.7874 \mathrm{~mm})$. It is advisable to mention that the thickness of the conducting films of these plates is not transcendent or important for the synthesis since the film located towards the inner structure it is totally removed and that placed towards the outer structure is used only as a ground plane, and hence it is not necessary to consider their thicknesses and electrical characteristics.

Thus, the total distance between the upper and lower ground planes, denoted in Figs. 5 as B, is equal to $1.8628 \mathrm{~mm}$, which becomes from the addition of $0.7874+0.017+0.254+$ $0.017+0.7874 \mathrm{~mm}$, where $0.7874 \mathrm{~mm}$ is the thickness of the lower and upper dielectrics, $0.017 \mathrm{~mm}$ is the thickness of conducting films and $0.254 \mathrm{~mm}$ is the thickness of the central plate dielectric. With this data available is now possible to realize the synthesis of each section by using the codes containing the Bahl's and Shelton's equations (for small couplings).

These results are respectively shown in Tables 3 and 4 . As in previous tables, $c_{v n}$ denotes the voltage coupling coefficients and $n$ is the number of sections, $\varepsilon_{r}$ is the dielectric's relative permittivity (the same for the three plates) and $w_{\mathrm{c}}$ (small couplings) is the amount of dislodgement if the displacement has not a negative value (which should indicates not dislodgement and hence, will be only the distance separating one line of the other. Thus, once the widths of the lines are calculated, it remains to calculate the values of the lengths. Also, as all the sections should have a length of $\lambda / 4$, at the central frequency, then, it is only necessary to define which one will be this frequency at the operation bandwidth. After that, and owing the final bandwidth for all de six-port was of $3.5 \mathrm{GHz}$ (from 1.25 to $4.75 \mathrm{GHz}$ ), then, the central frequency will be of $3 \mathrm{GHz}$. For this frequency and considering a relative permittivity of $\varepsilon_{r}=2.2$, the lengths (L) will be of approximately 16.855 $\mathrm{mm}$. For the lines interconnecting the two $8.34 \mathrm{~dB}$ couplers, sections (Li) of $5 \mathrm{~mm}$ length will be employed as those used by Rao for his synthesis. These sections should have the same width than the $8.34 \mathrm{~dB}$ coupler sections that interconnects, in this case $1.5103 \mathrm{~mm}\left(w_{1}\right)$. All the others lines employed for the interconnection between the couplers are synthesized to have an impedance of $50 \Omega$ corresponding to a width $(w)$ of $1.32 \mathrm{~mm}$, see Fig. 8 .

Table 3. Width $(w)$ of the central section, for maximum coupling (BCS), calculated by means of the Bahl's equations.

\begin{tabular}{|c|c|c|c|c|}
\hline$c_{v 4}$ & $\varepsilon_{r}$ & $\mathrm{~B}(\mathrm{~mm})$ & $s(\mathrm{~mm})$ & $w_{4}(\mathrm{~mm})$ \\
\hline 0.61881 & 2.2 & 1.8628 & 0.254 & 1.0397 \\
\hline
\end{tabular}

Table 4. Width $w, w_{\mathrm{o}}$ and $w_{\mathrm{c}}$ of the remaining sections, for small coupling (OCS), calculated by means of the Shelton's equations.

\begin{tabular}{|c|c|c|c|c|c|c|}
\hline$c_{v n}$ & $\varepsilon_{r}$ & $\begin{array}{c}\mathrm{B} \\
(\mathrm{mm})\end{array}$ & $\begin{array}{c}s \\
(\mathrm{~mm})\end{array}$ & $\begin{array}{c}w_{n} \\
(\mathrm{~mm})\end{array}$ & $\begin{array}{c}w_{o n} \\
(\mathrm{~mm})\end{array}$ & $w_{c n}(\mathrm{~mm})$ \\
\hline $\begin{array}{c}c_{v 3}= \\
0.218537\end{array}$ & 2.2 & 1.8628 & 0.254 & 1.3752 & 1.5123 & -0.1371 \\
\hline $\begin{array}{c}c_{v 2}= \\
0.083046\end{array}$ & 2.2 & 1.8628 & 0.254 & 1.4897 & 2.1421 & -0.6524 \\
\hline $\begin{array}{c}c_{v 1}= \\
0.024873\end{array}$ & 2.2 & 1.8628 & 0.254 & 1.5103 & 2.8680 & -1.3577 \\
\hline
\end{tabular}

Once the dimensions of the sections are obtained, the next step is the conformation the $3 \mathrm{~dB}$ coupler structure. Fig. 8 presents the actual size configuration of such a coupler not considering the depth of the central layer; this is, presented only in 2D. The red color sections correspond to the superior face and the blue ones to the inferior face, both on the central layer. On the same Fig. 8, the values of widths $w_{n}$, the separations $w_{\mathrm{cn}}$ and the lengths of each one of the lines L, are indicated in $\mathrm{mm}$. Because the lines are overlapped and one corresponding to the central section cover totally to the other, it was considered important to show separately the geometries of each one of the planes as in Figs. 9(a) and 9(b). 


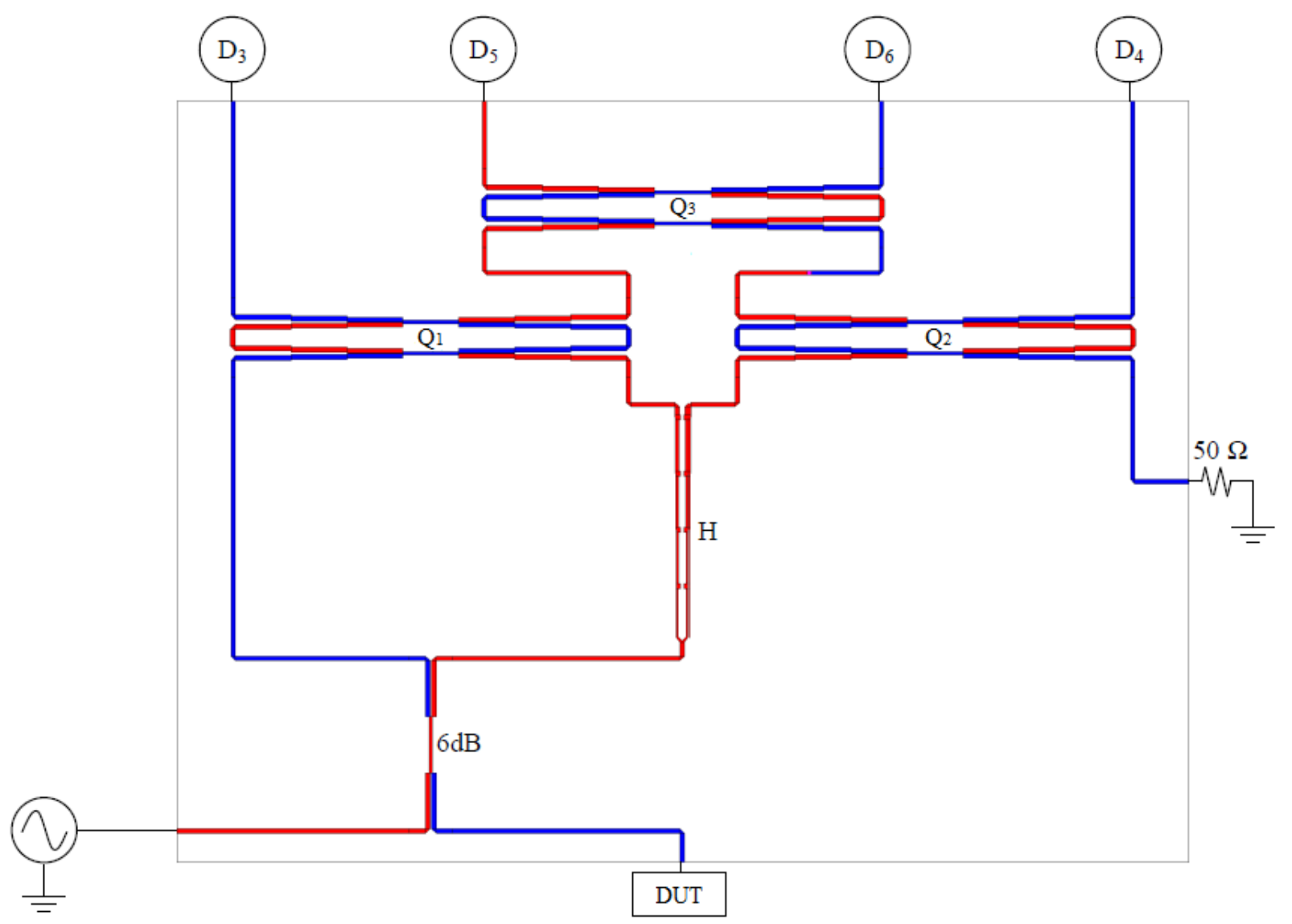

Figure 1. Complete six-port reflectometer structure, including the source, the DUT, the $50 \Omega$ load and the diode outputs.

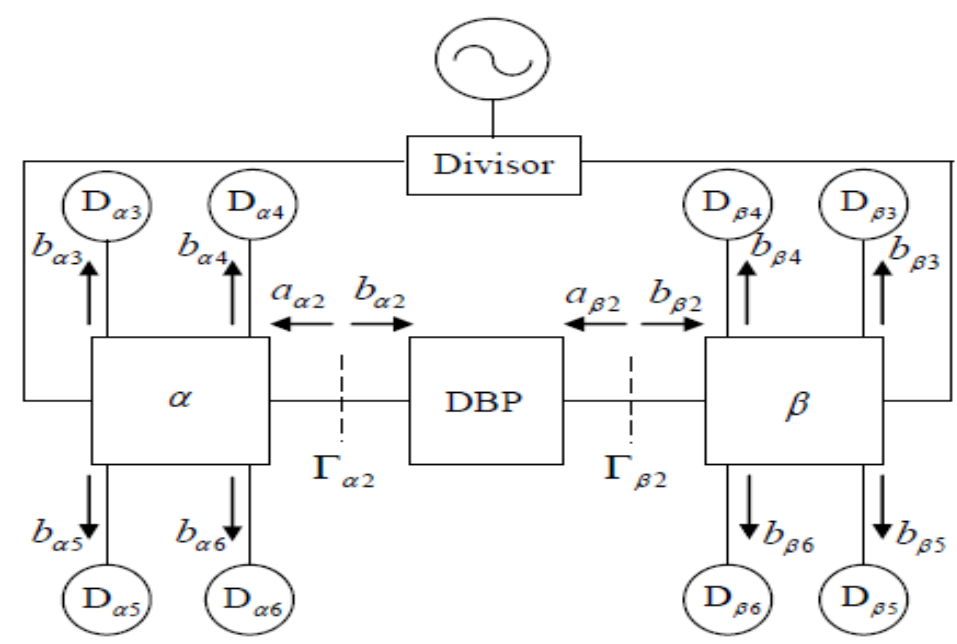

Figure 2. A dual six-port network analyzer.

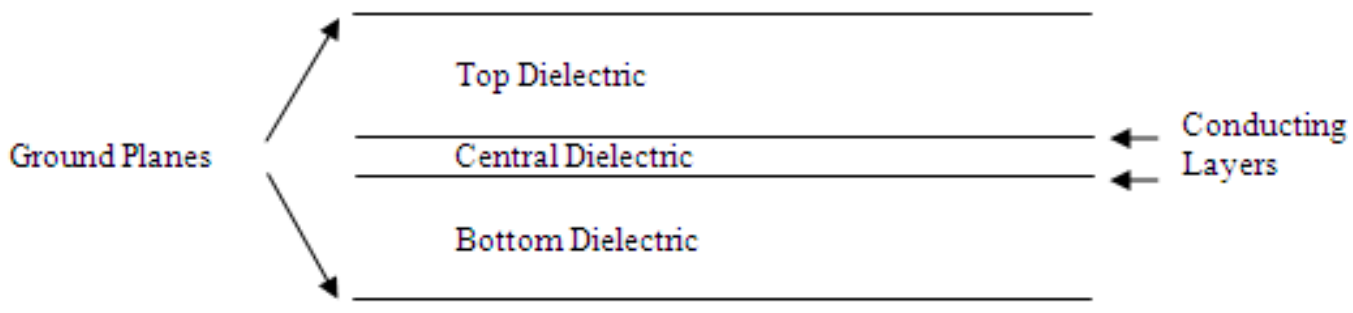

Figure 3. Structure of three layers employed to design directional couplers. 

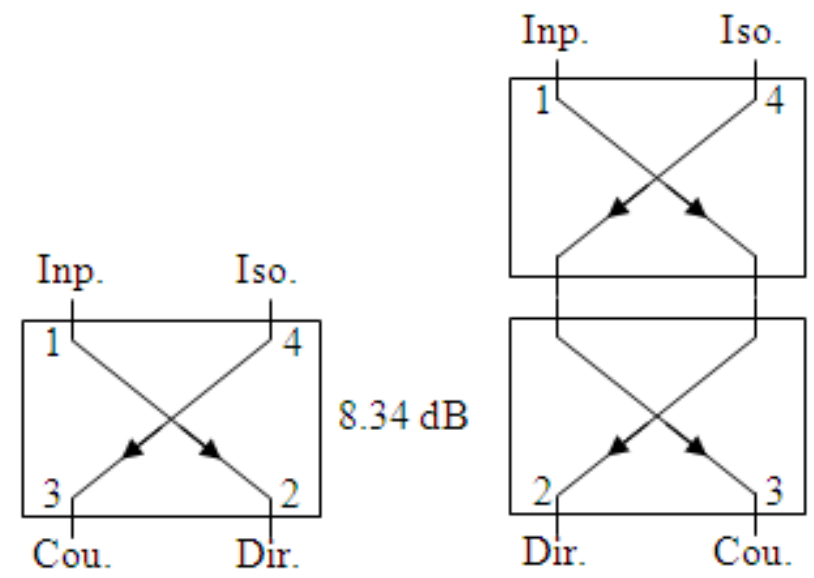

Figure 4. A $3 \mathrm{~dB}$ coupler obtained with the cascade interconnection of two $8.34 \mathrm{~dB}$ couplers.

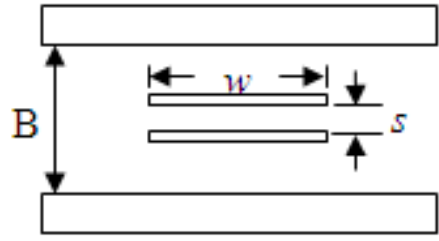

"Broadside"

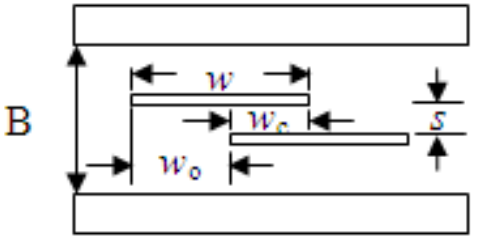

"Offset"

(a)

(b)

Figure 5. The two configurations of the triplate arrangement for the coupling sections. (a) Maximum coupling section. "Broadside Coupled Stripline" (BCS). (b) Small coupling section. "Offset Coupled Stripline" (OCS).

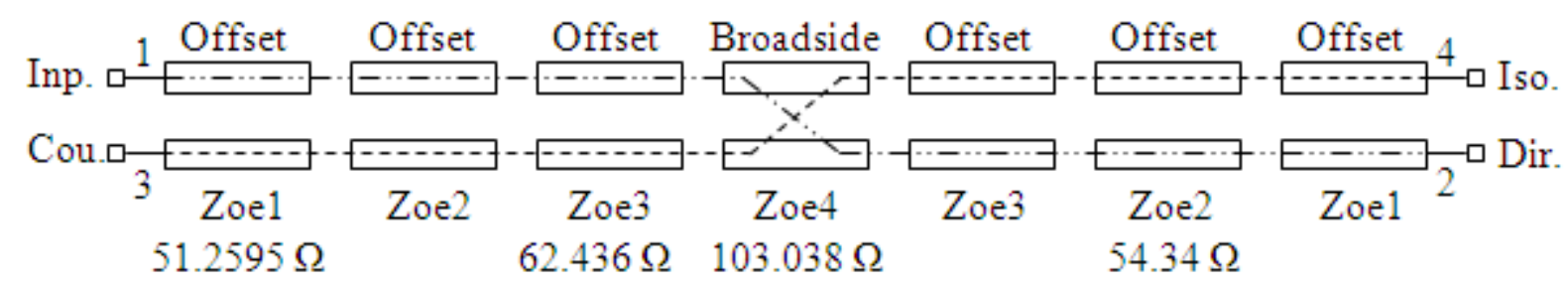

Figure 6. Seven sections $8.34 \mathrm{~dB}$ coupler.

Dir.

Values of coupling

Cou.

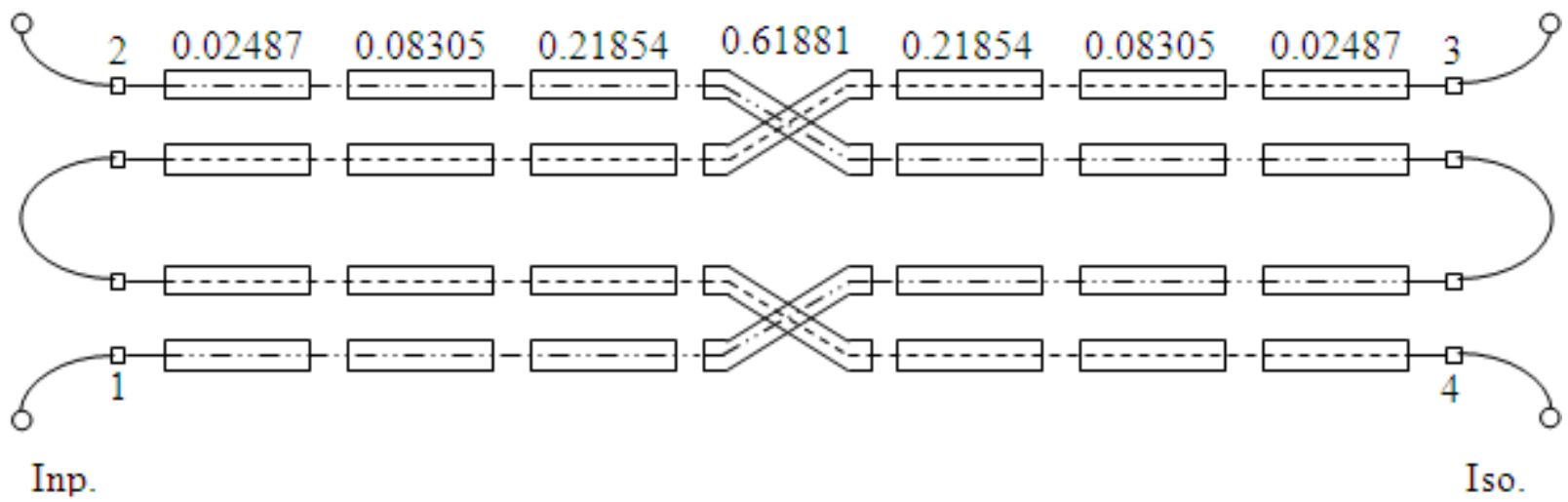

Figure 7. A $3 \mathrm{~dB}$ coupler composed by two of $8.34 \mathrm{~dB}$ with seven sections in tandem. 


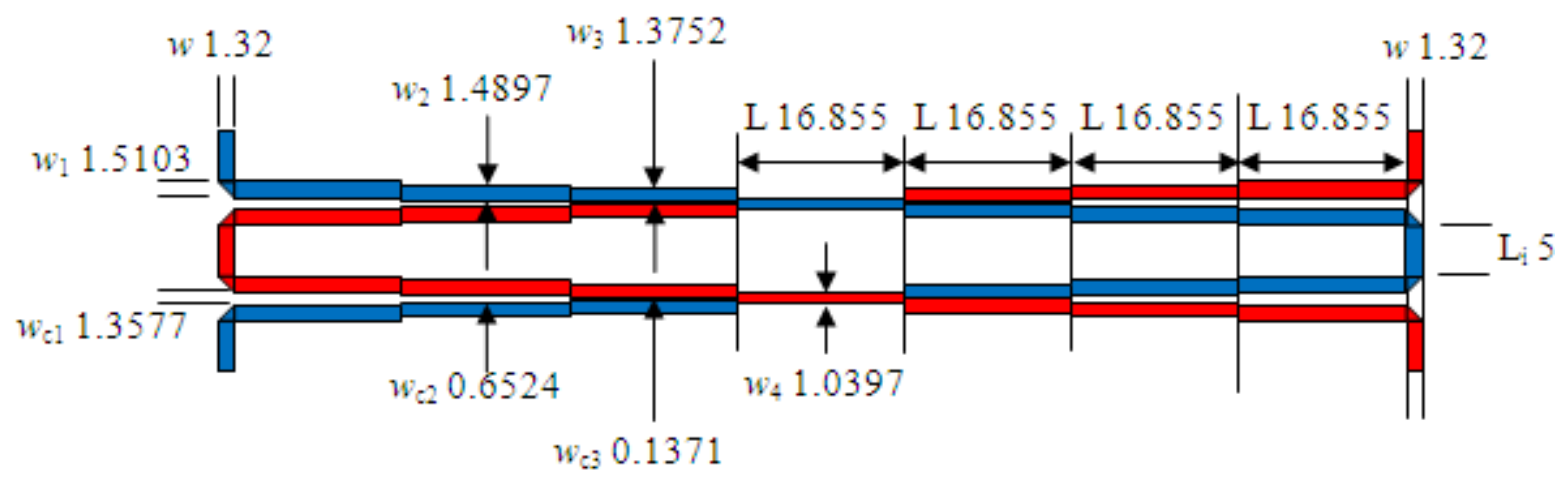

Figure 8. A $3 \mathrm{~dB}$ coupler composed by two of $8.34 \mathrm{~dB}$ with seven sections in tandem for an operating central frequency of $3 \mathrm{GHz}$ (actual size).

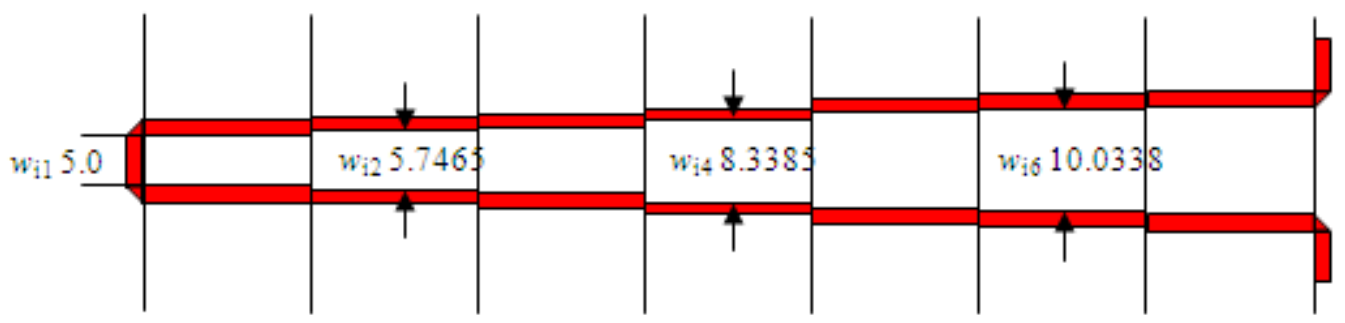

(a)

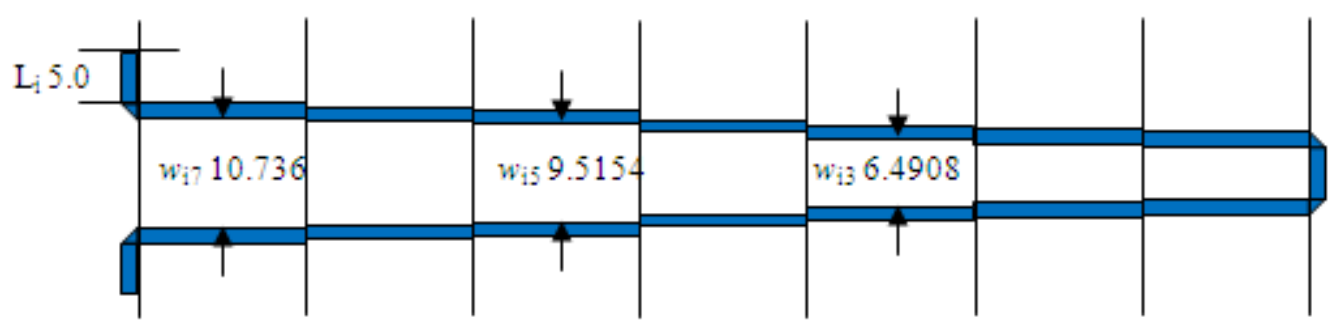

(b)

Figure 9. The $3 \mathrm{~dB}$ coupler of Fig. 8, separated (actual size). (a) Traces of the superior face. (b) Traces of the inferior the face.

\section{Design of the Quadrature $6 \mathrm{~dB}$ Coupler}

To design the $6 \mathrm{~dB}$ directional coupler, a procedure similar to that used in previous section (to synthesize the $8.34 \mathrm{~dB}$ couplers) is now employed. The coupling of $6 \mathrm{~dB}$ can be achieved with only one coupler without require of tandem arrangements. However, because couplers of this kind can't be realized with seven sections and the dimensions already determined for the dielectric plates, then, a combination of sections/bandwidth that could be realized with those dimensions was searched on Cristal tables. By using these tables, it was found that a $6 \mathrm{~dB}$ coupler with three sections and ripple of $\pm 0.30 \mathrm{~dB}$ can be realized to provide a bandwidth $(B)$ of approximately 3.8 times the initial frequency $\left(f_{1}\right)$. These values are presented in Table 5 . It is opportune to mention now, that although the $6 \mathrm{~dB}$ coupler synthesized by means of the Cristal tables will result in quadrature $\left(90^{\circ}\right)$, this is not mandatory or necessary since this coupler is used only to distribute the signal among the DUT and the other signal separators and the phase shift will be the same on all them. The central section is synthesized for maximum coupling (BCS) and the edge sections (which have equal even mode characteristic impedance) are calculated for small coupling (OCS). The Fig. 10 shows the configuration of a $6 \mathrm{~dB}$ three sections coupler.

Table 5. Even impedance, normalized zoe and not normalized Zoe, for an $8.34 \mathrm{~dB}$ coupler of three sections, with a normalizing impedance of $50 \Omega$.

\begin{tabular}{|c|c|c|c|}
\hline Ripple in $\mathrm{dB}$ & zoe1 & zoe2 & $B$ \\
\hline \pm 0.30 & 1.13625 & 2.18999 & 3.83226 \\
\hline $\mathrm{Z} 0=50 \Omega$ & Zoe1 & Zoe2 & \\
\hline & $56.8125 \Omega$ & $109.50 \Omega$ & \\
\hline
\end{tabular}

Next, by using (1), the coupling values are calculated and shown in Table 6 and Fig. 11. The same as in the case of the 3 $\mathrm{dB}$ coupler and with the availability of Table 6 values, it is now feasible to realize the synthesis of the $6 \mathrm{~dB}$ coupler by employing the code programs with the Bahl's equations (using zoe2, for maximum coupling BCS) and Shelton's equations (using zoe1, for small coupling). The results are presented in Tables 7 and 8 , and its distribution or configuration in Fig. 12. 
Table 6. Coupling coefficients for a 3 sections $6 \mathrm{~dB}$ coupler.

\begin{tabular}{|c|c|c|c|}
\hline Ripple in $\mathrm{dB}$ & zoe1 & zoe2 & $B$ \\
\hline \pm 0.30 & 1.13625 & 2.18999 & 3.83226 \\
\hline zoe $^{2}$ & 1.291064 & 4.796056 & \\
\hline$c_{v n}$ & 0.1270432 & 0.654938 & \\
\hline
\end{tabular}

Unfortunately, because the impossibility to find the appropriated values for the even impedances, the bandwidths and the ripple value, in accordance to the set upped combination for the dielectric thicknesses, then was not possible neither attain a six-port structure with the bandwidth of the original idea ( 2 to $8 \mathrm{GHz}$ ). The coupler bandwidth $(B)$ is of approximately 3.83 times the initial frequency $\left(f_{1}\right)$.
Thus, if the lower frequency $\left(f_{1}\right)$ is of $1.25 \mathrm{GHz}$, when multiplied by $B$, the upper frequency $\left(f_{2}\right)$ becomes of approximately $4.75 \mathrm{GHz}$.

Table 7. Width ( $w$ ) of the central section, for maximum coupling (BCS), calculated by means of the Bahl's equations.

\begin{tabular}{|c|c|c|c|c|}
\hline$c_{v 2}$ & $\varepsilon_{r}$ & $\mathrm{~B}(\mathrm{~mm})$ & $s(\mathrm{~mm})$ & $w_{2}(\mathrm{~mm})$ \\
\hline 0.65494 & 2.2 & 1.8628 & 0.254 & 0.9235 \\
\hline
\end{tabular}

Table 8. Widths $w, w_{\mathrm{o}}$ and $w_{\mathrm{c}}$ of the remaining sections, for small coupling (OCS), calculated by means of the Shelton's equations.

\begin{tabular}{|c|c|c|c|c|c|c|}
\hline$c_{v 1}$ & $\varepsilon_{r}$ & $\begin{array}{c}\mathrm{B} \\
(\mathrm{mm})\end{array}$ & $\begin{array}{c}s \\
(\mathrm{~mm})\end{array}$ & $\begin{array}{c}w_{1} \\
(\mathrm{~mm})\end{array}$ & $\begin{array}{c}w_{o 1} \\
(\mathrm{~mm})\end{array}$ & $\begin{array}{c}w_{c 1} \\
(\mathrm{~mm})\end{array}$ \\
\hline 0.12704 & 2.2 & 1.8628 & 0.254 & 1.4610 & 1.8770 & -0.4160 \\
\hline
\end{tabular}

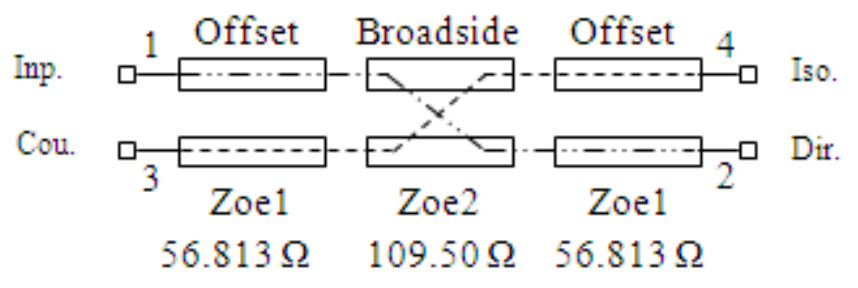

Figure10. Three sections $6 \mathrm{~dB}$ coupler.

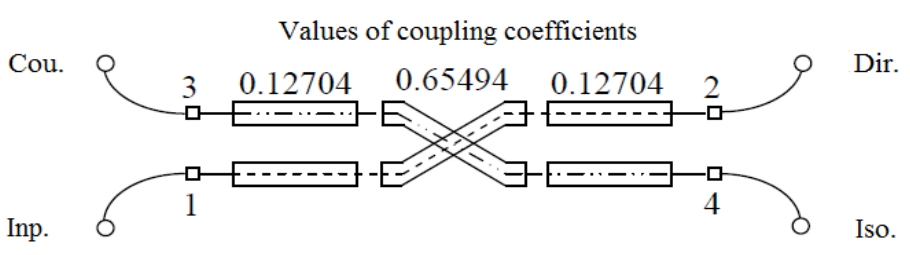

Figure 11. $6 \mathrm{~dB}$ coupler.

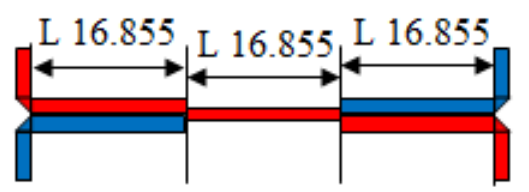

(a)

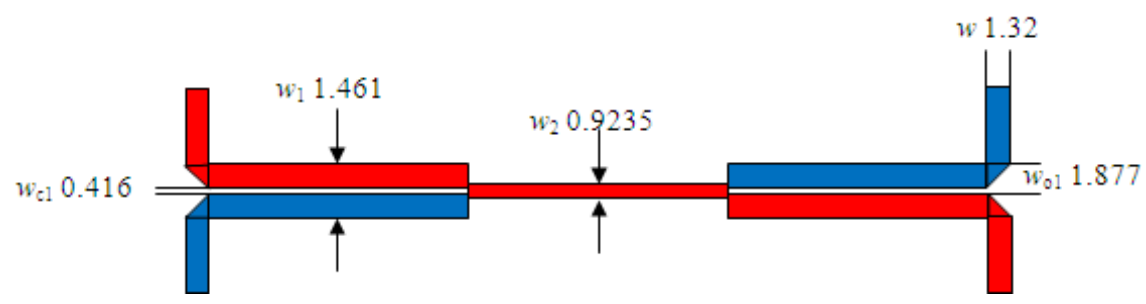

(b)
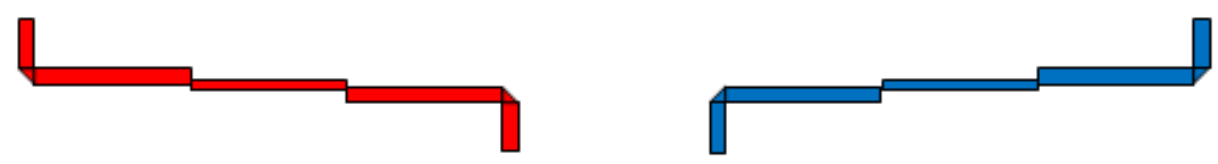

(c)

Figure 12. Three sections $6 \mathrm{~dB}$ quadrature coupler for an operation central frequency of $3 \mathrm{GHz}$. (a) Actual size figure. (b) Dimensions in mm. (c) (In red) traces of the upper face and (in blue) traces of the lower face. 


\section{Design of the In-phase $3 \mathrm{~dB}$ Coupler}

To design the three-port in-phase $3 \mathrm{~dB}$ directional coupler, a completely different procedure to that used in sections II and III to design the four-port couplers, is employed. The in-phase $3 \mathrm{~dB}$ coupler is designed to be constructed on a same plane as a multi-section Wilkinson coupler. The Wilkinson couplers of several sections are formed by transmission line pairs of $\lambda / 4$ length with a determined value of characteristic impedance and with shunt connected resistances on each one of the section unions as shown in Fig. 13. Unfortunately, those resistive elements (even if these are the very thin surface mounting discrete resistances) represent a problem for multi-layer designing, since the thicknesses of those resistances impedes the layer sandwich closes, leaving air fringes among them and hence altering the circuit final response. A possible solution to this problem is by locating small windows on the dielectric at the places where those resistances will be soldered. For the design of this coupler (the same as the previous ones) will be necessary to solve polynomial equations in order to obtain the characteristic impedance values for each section and the resistance values at the unions.

Fortunately, the characteristic impedance values, for couplers with 2 to 4 sections, can be directly obtained from the Young's tables [8]. Likewise, the values of the resistance unions can be obtained with the conductance equations, which are given as admittance functions by Cohn[9], for couplers considering until seven sections and relationships $\left(f_{2} / f_{1}\right)$ up to $10: 1$.

The bandwidth of the $3 \mathrm{~dB}$ in-phase coupler can be augmented (the same as the previous ones) by incrementing the number of sections and the complexity of the polynomials forming it. However, since the $6 \mathrm{~dB}$ coupler restricts the total six-port bandwidth to no more than 3.5 $\mathrm{GHz}$, it is necessary only to synthesize a $3 \mathrm{~dB}$ in-phase coupler for a bandwidth of $B=\left(f_{2} / f_{1}\right)=4$, corresponding to an arrangement of four sections or $N=4$.

Besides, given the nature of the multi-section Wilkinson coupler, it's even and odd mode analysis can be carried out as an arrangement of sections realizing impedance transforming between two resistive values collocated at its edges.

An in-phase $3 \mathrm{~dB}$ coupler for wide bandwidths (multi-section Wilkinson coupler with $N=4$ ) can be conceived as a stepped impedance transformer with a transformation relation of $2: 1(R=2)$. In this way, to synthesize the $3 \mathrm{~dB}$ in-phase coupler, the even mode bisected circuit proposed by Cohn[9] is used. Thus, with the available data of the bandwidth $(4: 1)$ and the impedance relation $R=2$ the values of $z_{1}$, and $z_{2}$, can be searched on the Young's corrected tables [10] and calculate the values of $z_{3}$, and $z_{4}$ by using the equations proposed by himself (Young) and given in his 1959 paper as

$$
z_{3}=\frac{R}{z_{2}}
$$

$$
z_{4}=\frac{R}{z_{1}}
$$

The results are shown in Table 9. Thus, once the characteristic impedance values of each one of the sections are obtained, these are converted to admittances and used on the Cohn's presented equations (17), (19), (20), (21) and (22) to calculate the shunt conductance values (or inversely their resistances). These equations are re-written next.

$$
\begin{aligned}
& T_{k}=\frac{4 Y_{k-1} Y_{k}}{\left(Y_{k-1}+Y_{k}+2 G_{k}\right)^{2}}, \text { for } k=1 \ldots N, \\
& G_{1}=1-Y_{1}, \\
& G_{k}=\frac{Y_{k-1}-Y_{k}}{Y_{k-1} T_{1} T_{2} \ldots T_{k-1}}, \text { for } k=2 \ldots N-1,
\end{aligned}
$$

where $G_{k}$ is the conductance value for the $k^{\text {th }}$ resistance, $Y_{k}$ is the $k^{\text {th }}$ section admittance value and $T_{k}$ is the $k^{\text {th }}$ section transmission coefficient

$$
G_{N}=\frac{\frac{1}{2} Y_{N^{2}-1}}{-2 G_{N-1}+\frac{Y_{N^{2}-2}}{-2 G_{N-2}+\frac{Y_{N^{2}-3}}{\frac{\ddots}{-2 G_{2}+\frac{Y_{1^{2}}}{-2 G_{1}+1+0.7\left(S_{e, 90^{\circ}}-1\right)}}}}},
$$

where $S_{e, 90^{\circ}}$ is the value of the voltage standing wave ratio (VSWR) for the even mode of a stepped impedance transformer when $\phi=90^{\circ}$, this is, when the sections length be of $\lambda / 4$. For the case of an odd $N$ value, $S_{e, 90^{\circ}}=1$ and for an even $N$ value $S_{e, 90^{\circ}}=S_{e m}$, where $S_{e m}$ is the maximum ripple value within the bandwidth. The resistance values are presented in Table 10.

Table 9. The values of the normalized characteristic impedances $\left(\boldsymbol{z}_{1}, \boldsymbol{z}_{2}, \boldsymbol{z}_{3}\right.$ and $\left.\boldsymbol{z}_{4}\right)$ and not normalized $\left(\mathbf{Z}_{1}, \mathbf{Z}_{2}, \mathbf{Z}_{3}\right.$ and $\left.\mathbf{Z}_{4}\right)$ corresponding to a four section Wilkinson coupler synthesized for a bandwidth of $4: 1$, obtained by employing Young's tables.

\begin{tabular}{|c|c|c|c|c|}
\hline $\boldsymbol{R}$ & $\boldsymbol{z}_{\mathbf{1}}$ & $\boldsymbol{z}_{\mathbf{2}}$ & $\boldsymbol{z}_{\mathbf{3}}$ & $\boldsymbol{z}_{\mathbf{4}}$ \\
\hline 2 & 1.11571 & 1.29572 & 1.54354 & 1.79258 \\
\hline $\mathbf{Z 0}=\mathbf{5 0} \mathbf{\Omega}$ & $\mathbf{Z}_{\mathbf{1}}$ & $\mathbf{Z}_{\mathbf{2}}$ & $\mathbf{Z}_{\mathbf{3}}$ & $\mathbf{Z}_{\mathbf{4}}$ \\
\hline & 55.7855 & 64.786 & 77.177 & 89.629 \\
\hline
\end{tabular}

Table 10. Values of the shunt resistances for each one of the unions between two sections. Calculated by employing the Cohn's equations.

\begin{tabular}{|c|c|c|c|c|}
\hline $\boldsymbol{S}_{\boldsymbol{e m}}$ & $\boldsymbol{z}_{1}$ & $\boldsymbol{z}_{\mathbf{2}}$ & $\boldsymbol{z}_{3}$ & $\boldsymbol{z}_{\mathbf{4}}$ \\
\hline 1.10 & 1.11571 & 1.29572 & 1.54354 & 1.79258 \\
\hline & $\mathbf{R 1}$ & $\mathbf{R 2}$ & $\mathbf{R 3}$ & $\mathbf{R 4}$ \\
\hline & $482.1148 \Omega$ & $291.5557 \Omega$ & $172.5999 \Omega$ & $103.1716 \Omega$ \\
\hline
\end{tabular}

From these values, the $3 \mathrm{~dB}$ in-phase coupler can be 
designed. The impedance values are employed to calculate the line widths in each one of the sections. The synthesis is considered to be realized on stripline technology, because the coupler is immersed on a tri-layer, this is, embedded in the dielectric and between the two ground planes. It is important to be aware that because this geometry is not equidistant between both ground planes, this is, at the center of the structure, but shifted a little be toward some of the planes, then it is necessary to calculate the lines width by using codes for analysis and/or synthesis of asymmetrical striplines. Thus, as will be seen, although the vertical shifting apparent to be small (only of $0.127 \mathrm{~mm}$ respect to the center), in fact this generates an appreciable difference among the results obtained for symmetrical and asymmetrical "striplines" $[11,12,13]$. For the synthesis of the $w$ widths, the following values were utilized: (conductor thickness) $\mathrm{T}=0.017 \mathrm{~mm}$, distance towards the nearest ground plane $\mathrm{H} 1=0.7874 \mathrm{~mm}$, distance towards the farthest ground plane $\mathrm{H} 2=1.0584 \mathrm{~mm}$ and relative permittivity $\varepsilon_{r}=2.2$.

It is opportune to mention that owing the programs which are available in $[11,12,13]$, are useful for the analysis only, then, to obtain the stripline width values $w_{n}$ corresponding to the Table 10 , it was necessary to vary those widths to find each one of the desired impedance values. The widths are shown in Table 11.

For the resistance values given in Table 10, surface mounting resistive elements with suitable dimensions to be integrated on the coupler were searched. These dimensions shouldn't be too small in order to impede the lines of each section be near one of the other and thus avoid couplings among them, but neither should be too large because the plate sandwich couldn't be closed and will be necessary to use windows which could be larger instead of small as mentioned at the beginning of this section.

Table 11. Values of the line widths for each section. Calculated by means of programs for asymmetric striplines.

\begin{tabular}{|c|c|c|c|c|c|}
\hline $\mathbf{T}(\mathrm{mm})$ & $\mathbf{H 1}(\mathrm{mm})$ & $\mathbf{H 2}(\mathrm{mm})$ & $\boldsymbol{\varepsilon}_{\boldsymbol{r}}$ & $\mathbf{Z}_{\boldsymbol{n}}(\Omega)$ & $\boldsymbol{w}_{\boldsymbol{n}}(\mathrm{mm})$ \\
\hline 0.017 & 0.7874 & 1.0584 & 2.2 & 55.7855 & 1.145 \\
\hline 0.017 & 0.7874 & 1.0584 & 2.2 & 64.786 & 0.910 \\
\hline 0.017 & 0.7874 & 1.0584 & 2.2 & 77.177 & 0.662 \\
\hline 0.017 & 0.7874 & 1.0584 & 2.2 & 89.629 & 0.479 \\
\hline
\end{tabular}

In this way, it was decided that the proper surface mounting resistances should be $2 \mathrm{~mm}$ length and $1.25 \mathrm{~mm}$ width. The available commercial values were: $102 \Omega$ instead of $103.1716 \Omega, 174 \Omega$ instead $172.6 \Omega, 270 \Omega$ instead of $291.56 \Omega$ and $487 \Omega$ instead of $482.115 \Omega$. Besides, in order these resistances could be permanently soldered to the plate, some conducting areas among the section unions were specifically assigned for such a task. Next, the actual size geometry of the $3 \mathrm{~dB}$ in-phase coupler (Fig. 14) and its dimensions in mm (Fig. 15) are presented. Theoretically, the bandwidth for this coupler should have a relation of $4: 1$, thereby if the lower frequency is of $1.25 \mathrm{GHz}$, the upper frequency will be of $5 \mathrm{GHz}$.

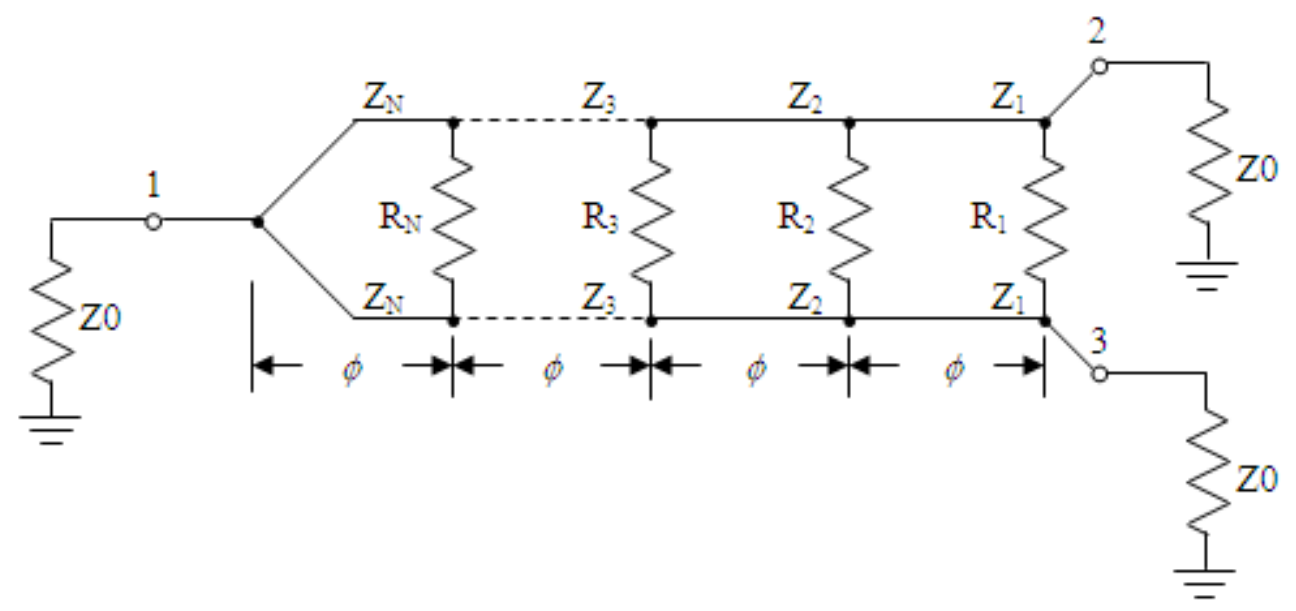

Figure 13. In-phase $3 \mathrm{~dB}$ coupler.

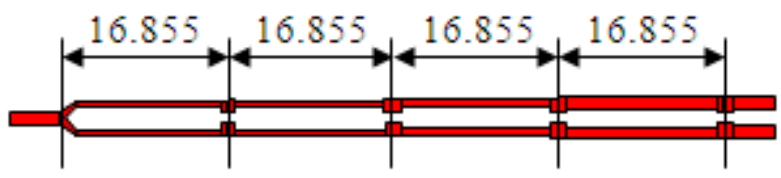

Figure 14. The length ( $\mathrm{mm}$ ) of the $3 \mathrm{~dB}$ in-phase coupler, designed for a central frequency of $3 \mathrm{GHz}$ (actual size). 


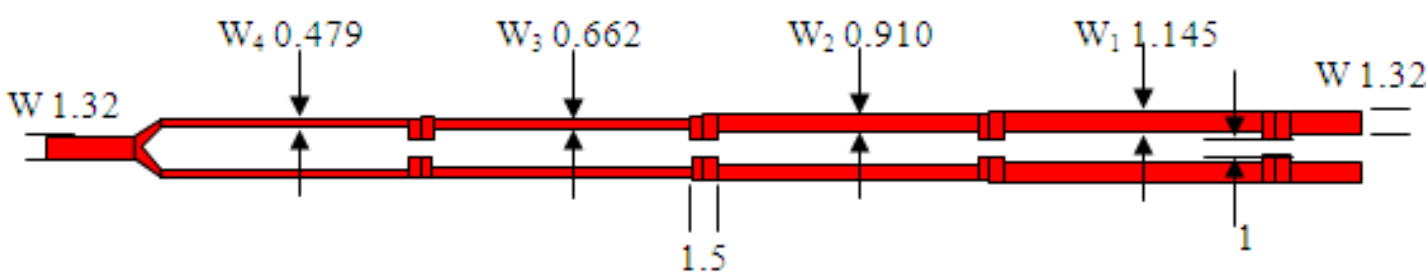

Figure 15. Dimensions (mm) of the $3 \mathrm{~dB}$ in-phase coupler.

\section{Incorporation of the $Q 1, Q 2, Q 3,6 \mathrm{~dB}$ and $H$ Signal Couplers onto the Engen's Six-Port Structure (First Proposal)}

Now, having the dimensions of all signal couplers composing the six-port structure, these can be incorporated onto the Engen's first proposal. Since the geometric traces of Q1, Q2, Q3 and $6 \mathrm{~dB}$ are located on both faces of the Duroid $5880^{\circledR}$ plate and the geometric trace of $\mathrm{H}$ in only one face, it will be unavoidable to realize the interconnection between this faces trying to obtain the best location for such a couplers. Thus, to carry out the couplers incorporation it was searched, as close to possible, that the interconnection traces among those were symmetric, mainly on the parts in which such traces feed to circuits with in-phase signals. These traces can be identified at the input of couplers Q1 and Q2, which receive the signal from coupler $\mathrm{H}$ at inputs of coupler Q3, which are connected with the outputs of couplers Q1 and $\mathrm{Q} 2$, and at the outputs toward the diodes $\mathrm{P}_{3}, \mathrm{P}_{4}, \mathrm{P}_{5}$ y $\mathrm{P}_{6}$ (Fig. 16).

To get the previously mentioned characteristics, avoiding undesirable couplings among the signals of the couplers, it was necessary take into account the Duroid $5880^{\circledR}$ commercial plate dimensions in order to allow enough spacing among the coupler separations, among the couplers and their connections, and among the connections and the connector endings.

Besides, since the $\mathrm{H}$ coupler providing the signal to the $\mathrm{Q} 1$ and Q2 couplers has to be mandatorily implemented on a sole plane, then for its incorporation will be necessary to connect the upper face with the lower face. To realize this connection, one of the Q3 inputs was chosen. This problem should be solved by connecting the upper face line with the lower face line by means of a thru-hole [14]. The total surface required to implement a six-port structure is a half of a commercial Duroid $5880^{\circledR}$ plate of 18 " x 12 ".

\section{Electromagnetic Validation}

In order to do a confident validation of the circuit and network analyses results, an electromagnetic simulation procedure was performed by using a reputed commercial software based on the finite element method. The software was obtained via a temporary license of the ANSYS HFSS package of ANSYS, Inc. Fig. 17 shows (top to bottom), the input signal, coupling, isolation and directivity for a $3 \mathrm{~dB}$ quadrature coupler on a bandwidth covering from 0.5 to 5.5 GHz. Fig. 18 shows (also top to bottom), the angles of coupling (red) and isolation (green) for a $3 \mathrm{~dB}$ quadrature coupler and the angle differences between coupling and isolation, also on bandwidth covering from 0.5 to $5.5 \mathrm{GHz}$. Fig 19 shows (as well top to bottom), the input signal, coupling 1 and coupling 2 for a $3 \mathrm{~dB}$ in-phase coupler on a bandwidth covering from 1.0 to $5.0 \mathrm{GHz}$. Fig 20 shows (similarly, top to bottom), the input signal, coupling, isolation and directivity for a $6 \mathrm{~dB}$ quadrature coupler on a bandwidth covering from 1.0 to $5.0 \mathrm{GHz}$. Finally, Fig. 21 shows the six-port reflectometer diode's responses on a bandwidth covering from 0.5 to $5.5 \mathrm{GHz}$. 


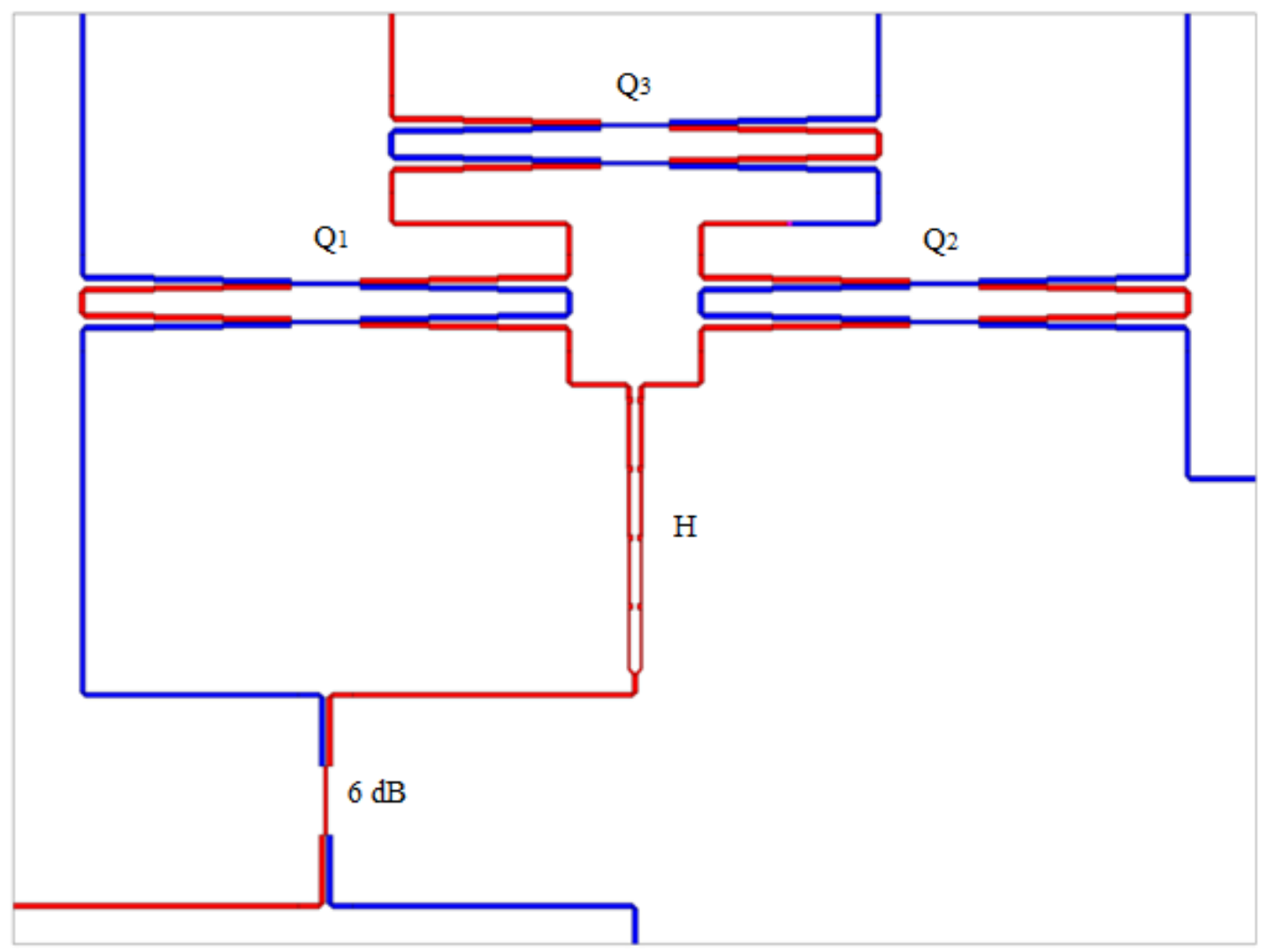

Figure 16. Complete six-port structure (both faces), based on the configuration of Engen's first proposal, for a bandwidth of $3.5 \mathrm{GHz}$ (from 1.25 to 4.75 $\mathrm{GHz}$ ).

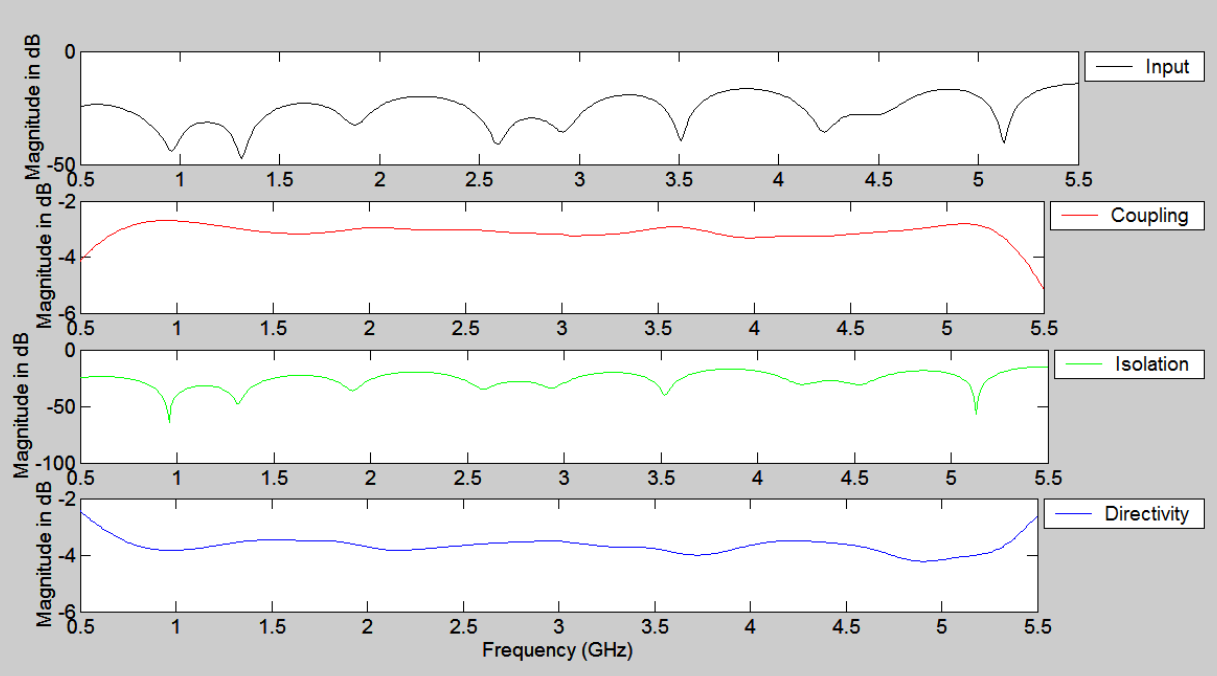

Figure 17. The input signal, coupling, isolation and directivity for a $3 \mathrm{~dB}$ quadrature coupler. 

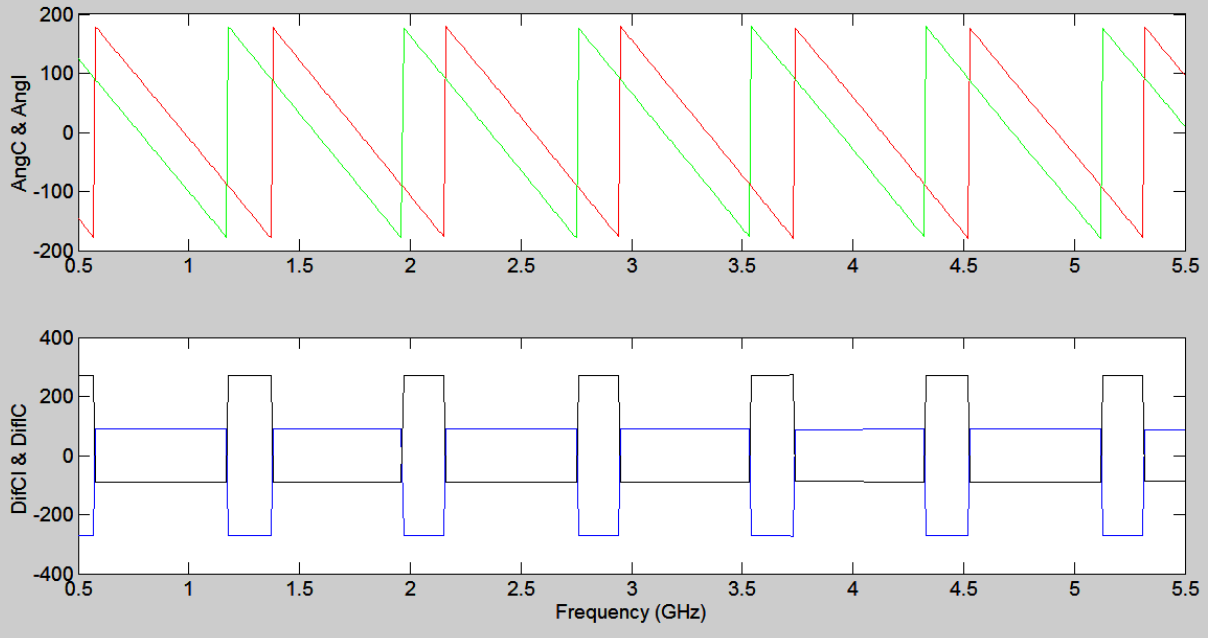

Figure 18. The angles of coupling (red) and isolation (green) for a $3 \mathrm{~dB}$ quadrature coupler.
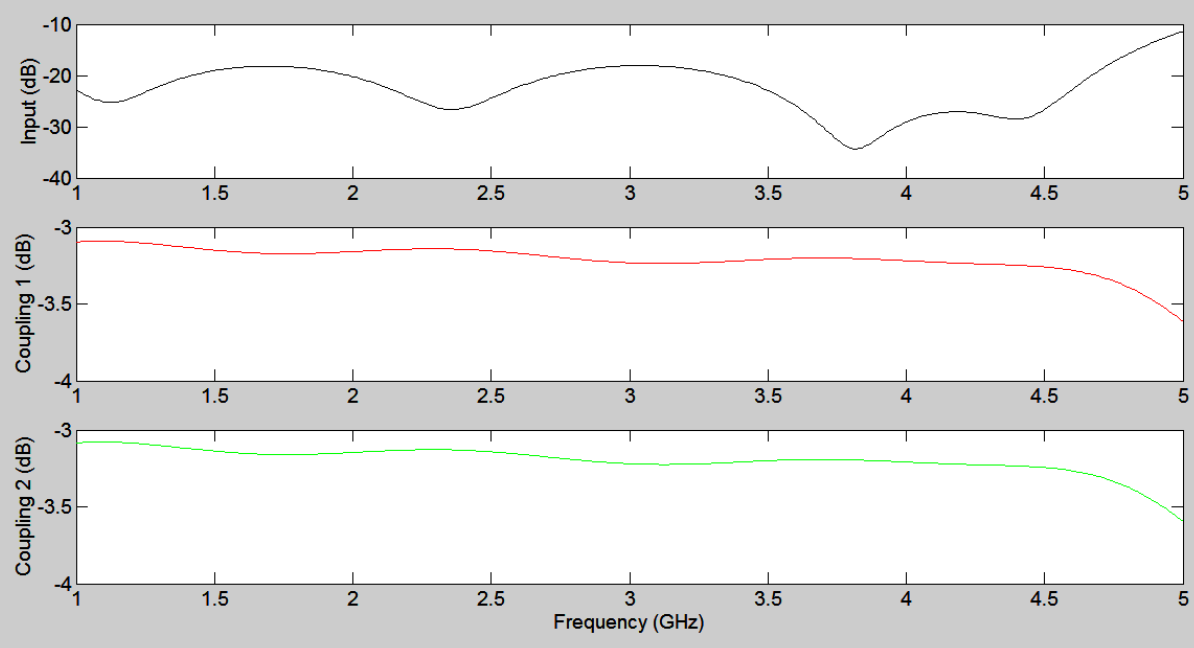

Figure 19. The input signal (black), coupling 1 (red) and coupling 2 (green) for a $3 \mathrm{~dB}$ in-phase coupler.
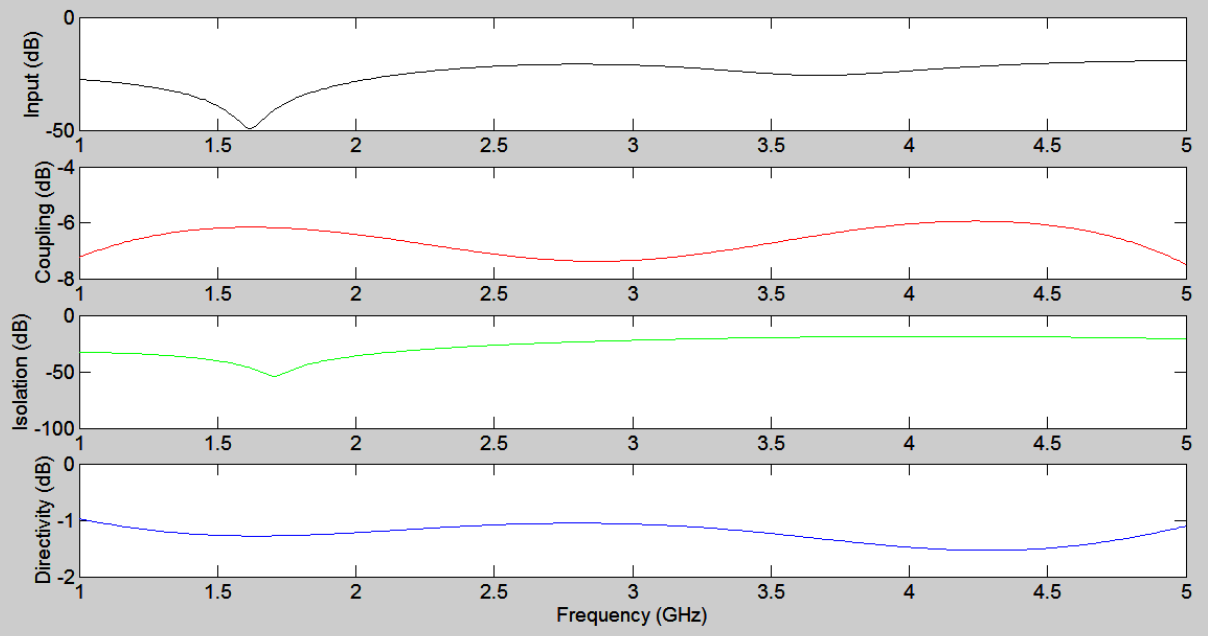

Figure 20. The input signal, coupling, isolation and directivity for a $6 \mathrm{~dB}$ quadrature coupler. 


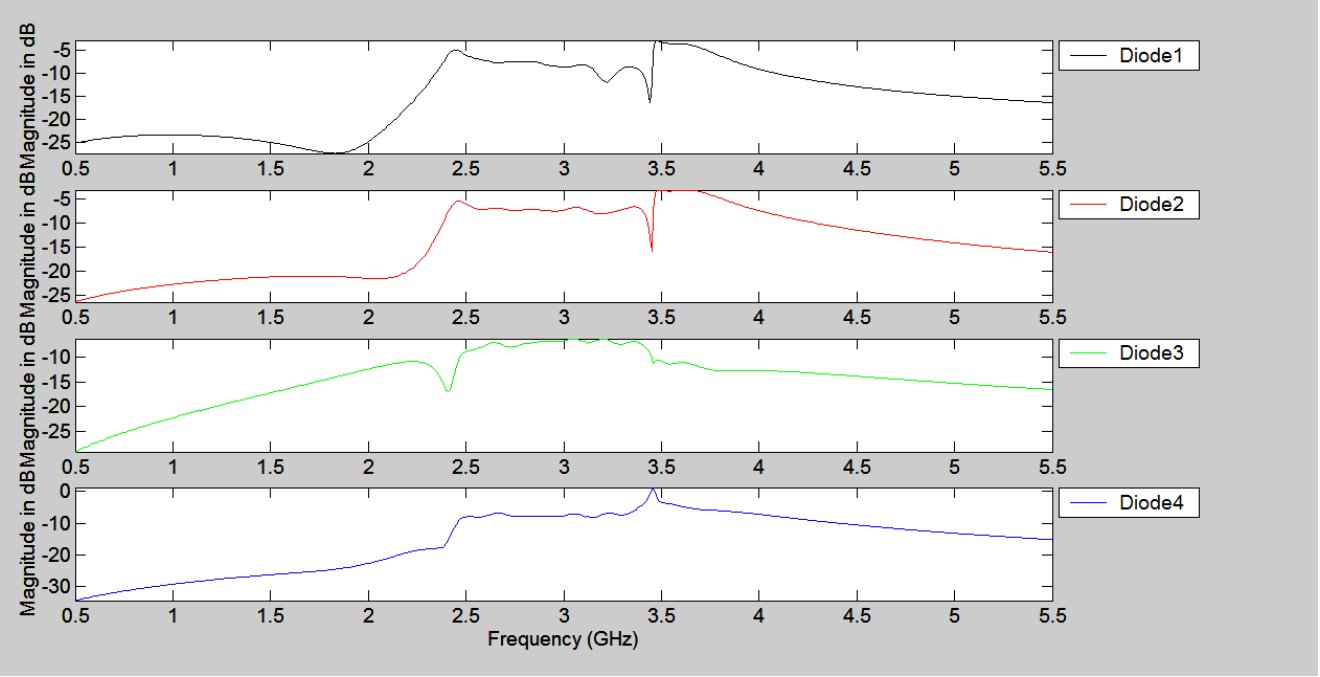

Figure 21. The six-port reflectometer diode's responses.

\section{Conclusion}

Look upon the circuit and network analysis here presented, but mainly considering the proposed physical implementation for some signal separation (micro and nano) structures constituting microwave six-port reflectometers and network analyzers, it is clear that a new kind of high frequency measuring instruments can be now conceived. Besides, the responses of each one of the circuits constituting a six-port network analyzer (a $6 \mathrm{~dB}$ directional coupler, a four stage $3 \mathrm{~dB}$ Wilkinson power divider and three quadrature couplers providing $3 \mathrm{~dB}$, which are formed by two $8.34 \mathrm{~dB}$ tandem couplers) were validated by a simple circuit analysis that performs a signal following from source to detectors. In addition, as a remarkable characteristic of the planar proposed (microstrip six-port structure), it is important to mention that, a bandwidth of $3.5 \mathrm{GHz}(1.25$ to $4.75 \mathrm{GHz}$ ) was obtained which is approximately fourteen times the obtained for the first proposal of a six-port structure [15].

There are three high-tech articles recently published in 2008 [16], 2010 [17] and 2012 [18] referencing [15].

\section{Acknowledgements}

This work was supported by PROMEP-SEP, México, under grant PROMEP/103.5/11/6834, IDCA 5197, UDG-CA-424

\section{REFERENCES}

[1] Shelton J. P., Van Wagoner R. and Wolfe J. J. "Tandem couplers and phase shifters: a new class of unlimited bandwidth components," in 1964 14th Ann. Symp., USAF Antenna Research and Development Program, sponsored by Air Force Lab., Wright-Patterson AFB, Dayton, Ohio, held at
Monticello, Ill., or Microwave, vol. 4, pp. 14-19, Apr. 1965.

[2] Shelton J. P., "Impedances of Offset Parallel-Coupled Strip Transmission Lines," IEEE Trans. on Microwave Theory and Techniques, vol. MTT-14, no. 1, pp. 7-15, Jan. 1966.

[3] Cohn S. B., "A Class of Broadband Three-Port TEM-Mode Hybrids," IEEE Trans. on Microwave Theory and Techniques, vol. MTT-16, no. 2, pp. 110-116, Feb. 1968.

[4] Engen G. F. 1977 An improved circuit for implementing the six-port technique of microwave measurements, IEEE Trans. Microwave Theory Tech., vol. MTT-25, no. 12, pp. 1080-1083, Dec.

[5] Cristal E. G., Young L. "Theory and Tables of Optimum Symmetrical TEM-Mode Coupled-Transmission-Line Directional Couplers," IEEE Trans. on Microwave Theory and Techniques, vol. MTT-13, no. 5, pp. 544-558, Sep. 1965.

[6] Bahl I. J., and Bhartia P., "The Design of Broadside-Coupled Stripline Circuits," IEEE Trans. on Microwave Theory and Techniques, vol. MTT-29, no. 2, pp. 165-168, Feb. 1981.

[7] Rao P. S. 2008 How to design a broadband stepped quadrature hybrid coupler in triplate stripline configuration http://www.eetimes.com/design/microwave-rf-design/40190 12/How-to-design-a-broadband-stepped-quadrature-hybrid-c oupler-in-triplate-stripline-configuration.

[8] Young L. "Tables for Cascaded Homogeneous Quarter-Wave Transformers," IRE Trans. on Microwave Theory and Techniques, vol. MTT-7, pp. 233-237, Apr. 1959.

[9] Cohn S. B. "A Class of Broadband Three-Port TEM-Mode Hybrids," IEEE Trans. On Microwave Theory and Techniques, vol. MTT-16, no. 2, pp. 110-116, Feb. 1968.

[10] Young L 1960 "Correction/' IRE Trans. Microwave Theory and Techniques, MTT-8, pp. 243-244, March. (The "Correction" applies to $\mathrm{N}=4$ ).

[11] Online Available: http://www.eeweb.com/toolbox/asymmetri c-stripline-impedance

[12] Online Available: http://www.mantaro.com/resources/imped ance_calculator.htm\#asymmetric_stripline_impedance 
[13] Online Available: http://www.hughescircuits.com/index.php/ en/support/impedance-calculator

[14] Online Available: download.intel.com/education/highered/si gnal/ELCT762/Class23-24-_Vias_Connectors_and_Package s.ppt

[15] Dueñas Jiménez A. and Bonilla Barragán C. A., “On the Calibration of a Microwave Network Six-Port Reflection Analyzer," IEEE Trans. on Instrumentation and Measurement, vol. TIM-56, no. 5, pp. 1763-1769, Oct. 2007.

[16] Haddadi K., Wang M. M., Nouri K., Glay D., Tuami Lasri, "Calibration and Performance of Two New Ultra-Wideband
Four-Port-Based Systems" IEEE Trans. Microwave Theory and Techniques, vol. MTT-56, no. 12, pp. 3137-3142, Dec. 2008.

[17] Yao J. J., Yeo S. P., "Using the Monte Carlo approach to study effects of power measurement uncertainties on six-port reflectometer performance" Meas. Sci. Technol. 21 (2010) 025103 (7pp), Jan.2010.

[18] Haddadi K., Tuami Lasri, "Formulation for Complete and Accurate Calibration of Six-Port Reflectometer" IEEE Trans. Microwave Theory and Techniques, vol. MTT-60, no. 3, pp. 574-581, Mar. 2012. 